\title{
Aplicação de jogos funcionais na pré-protetização de paciente com desarticulação de quadril pós osteossarcoma: estudo de caso
}

Application of functional games in the pre-protetization of patient with post-osteosarcoma hip disarticulation: case study

Aplicación de juegos funcionales en la proteticización de paciente con desarticulación de cadera pos osteosarcoma: estudio de caso

\section{Resumo}

O Osteossarcoma (OS) é uma neoplasia maligna que afeta o tecido ósseo, sem causa aparente, acomete mais o esqueleto apendicular, principalmente fêmur e tíbia de crianças e adolescentes. $\mathrm{O}$ tratamento consta de cirurgias de ressecção do tumor ou amputação de membros, associados à quimioterapia. A protetização fortalecimento, alongamento, propriocepção, equilíbrio e coordenação visando à deambulação futura, independente. E acredita-se que a reabilitação através do uso de programas com jogos funcionais na reabilitação como Xbox360 Kinect ${ }^{\circledR}$ oferecem estímulos diferentes em relação às técnicas convencionais de tratamento fisioterápico, com o objetivo de avaliar os resultados do uso dos jogos funcionais na pré-protetização de paciente com desarticulação de quadril pós osteossarcoma. A amostra foi composta por 1 indivíduo adolescente, sexo masculino, onde foi aplicado avaliação de desempenho força muscular, equilíbrio e coordenação motora através do Videogame Xbox 360 acompanhado do sensor Kinect, com jogo o Adventure da marca Microsoft. Realizado 11 sessões. Para análise, foi utilizado o programa estatístico Microsoft Office Excel 2010 e tabela de planejamento terapêutico pré e pós-intervenção. Os resultados demonstram que houve diferença significativa em todos os objetivos previamente estabelecidos, ao ser comparado as médias em relação à avaliação realizada na seção inicial e na avaliação final realizada após a décima primeira sessão. Conclui-se que o presente trabalho evidenciou que a terapia com o Kinect se mostrou eficaz aos objetivos previamente estabelecidos que foram de analisar a influência dos mesmos perante a força, coordenação motora e equilíbrio em amputado unilateral de desarticulação de quadril pós-osteossarcoma.

Palavras-chave: Osteossarcoma; Pré-protetização; Xbox360 Kinect®.

\section{Abstract}

Osteosarcoma (OS) is a malignant neoplasm that affects bone tissue, with no apparent cause, affecting the appendicular skeleton, especially the femur and tibia of children and adolescents. Treatment consists of surgeries 
of tumor resection or limb amputation associated with chemotherapy. Strengthening, stretching, proprioception, balance and coordination, aiming at future, independent walking. It is believed that rehabilitation through the use of functional play programs in rehabilitation such as Xbox360 Kinect ${ }^{\circledR}$ offers different stimuli compared to conventional techniques of physiotherapeutic treatment. Objective: To evaluate the results of the use of functional games in the preprotection of patients with post-osteosarcoma hip disarticulation. Methodology: The sample was composed of 1 adolescent, male gender. It was applied performance evaluation muscle strength, balance and motor coordination through the Videogame Xbox 360 accompanied by the Kinect sensor, with the Adventure da brand Microsoft game. Made 11 sessions. For analysis, we used the statistical program Microsoft Office Excel 2010 and the table of therapeutic planning before and after intervention. Results: There was a significant difference in all the previously established objectives, when the means were compared in relation to the evaluation performed in the initial section and the final evaluation performed after the eleventh sessions. Conclusion: It is concluded that the present study showed that the Kinect therapy proved to be effective to the previously established objectives that were to analyze the influence of the same before the force, motor coordination and balance in unilateral amputee disarticulation of post-osteosarcoma hip.

Keywords: Osteosarcoma; Pre-prosthetics; Xbox360 Kinect®.

\section{Resumen}

El osteosarcoma (OS) es una neoplasia maligna que afecta el tejido óseo, sin causa aparente, afecta más el esqueleto apendicular, especialmente el fémur y la tibia de niños y adolescentes. El tratamiento consiste en cirugías de resección tumoral o amputación de extremidades, asociadas a quimioterapia. El fortalecimiento del ajuste, estiramiento, propiocepción, equilibrio y coordinación con miras a una futura deambulación independiente. Y se cree que la rehabilitación mediante el uso de programas con juegos funcionales en rehabilitación como Xbox360 Kinect ${ }^{\circledR}$ ofrecen diferentes estímulos en relación a las técnicas convencionales de fisioterapia, con el objetivo de evaluar los resultados del uso de juegos funcionales en el pre- ajuste de paciente con desarticulación de cadera después de osteosarcoma. La muestra estuvo conformada por 1 adolescente masculino, donde se aplicó la evaluación del desempeño de fuerza muscular, equilibrio y coordinación motora a través del Videojuego Xbox 360 acompañado del sensor Kinect, con el juego Adventure marca Microsoft. Realizó 11 sesiones. Para el análisis se utilizó el programa estadístico Microsoft Office Excel 2010 y la tabla de planificación terapéutica pre y post intervención. Los resultados demuestran que hubo una diferencia significativa en todos los objetivos previamente establecidos, al comparar las medias en relación a la evaluación realizada en el tramo inicial y en la evaluación final realizada después de la undécima sesión. Se concluye que el presente trabajo demostró que la terapia Kinect demostró ser efectiva para los objetivos previamente establecidos, que fueron analizar su influencia en la fuerza, la coordinación motora y el equilibrio en amputados unilaterales post osteosarcoma con desarticulación de cadera.

Palabras clave: Osteosarcoma; Preinstalación; Xbox360 Kinect®.

\section{Introdução}

Segundo Instituto Nacional do Câncer-INCA (2015), osteossarcoma é o tumor ósseo maligno primário mais comum, e pode ocorrer em qualquer faixa etária. Porém, atinge principalmente crianças, adolescentes e adultos jovens, portanto sua maior prevalência é crianças adolescentes principalmente durante a segunda década de vida, ou seja, durante a fase de crescimento na puberdade, assim representa $20 \%$ dos cânceres primários e $5 \%$ dos tumores da infância. Sua localização mais comum é na metáfise dos ossos longos que estão na fase de crescimento (como fêmur distal e tíbio proximal) e sua extensão varia em cada pessoa.

Segundo Camargo (2013), os sinais e sintomas mais comuns são: dor óssea progressiva, fadiga e dor noturna, seguidos de edema e limitação de movimentos, sintomas respiratórios são raros ao diagnóstico e estão presentes em casos de doença pulmonar avançada e as fraturas patológicas podem ser observadas em $15 \%$ dos casos. O diagnóstico se dá pela história clínica e exames complementares como cintilografia óssea com radioisótopos, Tomografia Computadorizada (TC), Ressonância Nuclear Magnética (RNM), além das biópsias de amostra dos tecidos lesionados. O estudo prévio do tipo de câncer através da biópsia tem permitido um diagnóstico mais preciso e menores complicações após cirurgias oncológicas Camargo (2013). Durante o tratamento do osteossarcoma infantil, a criança é submetida a vários exames, internações hospitalares prolongadas e diversas modalidades terapêuticas, tais como quimioterapia, radioterapia e cirurgia como a amputação. 
O termo amputação pode ser definido como sendo a retirada, geralmente cirúrgica, total ou parcial de um membro. A Desarticulação de quadril refere-se à retirada total o fêmur. Este procedimento leva a uma série de alterações cognitivas e funcionais na biomecânica corporal que podem interferir no cotidiano do amputado gerando, ainda, padrões de postura e de marcha. O fisioterapeuta desempenha um papel fundamental e indispensável na reabilitação de amputados de MMII, e o início precoce do tratamento apropriado poderá influenciar os resultados eventuais da reabilitação.

De acordo com as informações coletadas, segundo Amadio, (2000), na fase de pré-protetização e pós-protetização incluem: tornar o indivíduo o mais independente possível; favorecer a realização de atividades de vida diária, com o uso ou não da prótese; preparar o coto para a protetização; reintegrar o indivíduo na sociedade, com os objetivos de fortalecimento, alongamento, propriocepção, equilíbrio e coordenação visando à deambulação futura, independente.

O grande impacto começa com a o momento da pré-protetizacão, é uma fase demorada que os amputados passam, pois é o ciclo onde deve preparar o coto para receber a prótese, sendo que a prótese pode chegar dentre os 6 meses ou anos. Resende et al. (2004), ao realizar um estudo com o objetivo de descrever a configuração da rede social de pessoas com amputação de membros, verificaram que, quando um indivíduo perde um membro, ocorrem mudanças bruscas em sua vida e, consequentemente, o seu comportamento e maneira de agir são afetados diretamente. Esses indivíduos então têm como desafio ajustar-se psicologicamente à sua deficiência física para que a ela não se torne incapacitante.

Em regra, imaginem o adolescente está exposto a um ambiente que não correspondem, ao que seria o período da adolescência, ou seja, compreende diversas mudanças de ordem física e emocional como: mudanças corporais, crescimento físico e formação da identidade. Nessa etapa o sujeito realiza a transição para o mundo adulto por meio da progressiva independência em relação à família e crescente autonomia para fazer escolhas, além da ampliação das redes sociais. Quando o câncer acomete esses sujeitos surgem outras alterações: efeitos colaterais, distanciamento dos amigos, familiares e escola. Portanto, no contexto conturbado da adolescência, a submissão a um tratamento de câncer, produzirá um novo contexto representativo no desenvolvimento do sujeito. Segundo Camargo (2013), a constantes idas ao centro de tratamento expõem o adolescente à dor e ao sofrimento, o que pode interferir na sua capacidade funcional.

Diante desse contexto, para deixar a fisioterapia algo motivador e cheio de ganhos, e ao mesmo tempo trabalhar a préprotetização sem sair da essência do programa de reabilitação, faz-se necessário novas abordagens terapêuticas para auxiliar na reabilitação, como o uso dos jogos funcionais, a fim de capturar a atenção e motivar para a aprendizagem de novas tarefas motoras funcionais e/ou cognitivas, ou seja, trabalhar com ludicidade ou ludoterapia pode ser muito eficaz e divertida ao invés de maçante e entediante, estimulando a autoestima dessas crianças e adolescentes. Autores enfatizam, assim como Taylor et al. (2011), jogos que promovem a atividade do indivíduo como o Xbox 360 Kinect®e, exigem a movimentação, o uso do peso corporal do jogador para o controle do jogo, ou seja, a natureza ativa desses sistemas de jogos pode oferecer a terapeutas e pacientes uma série de potenciais benefícios para complementar as terapias tradicionais.

Como o videogame Xbox360 Kinect $®$, oferecem estímulos diferentes em relação às técnicas convencionais de tratamento fisioterápico, e, com isso, a criança, ou adolescente tenha mais disposição para enfrentar os desafios que a reabilitação exige, o videogame oferece um grande repertório de jogos que envolvem movimentos de diversos segmentos corporais em tarefas com diferentes níveis de complexidade motora e cognitiva. Sua principal vantagem é que sua tecnologia permite a interação do jogador com o jogo, sem utilização de controles manuais, por meio de um sistema de reconhecimento de gestos por câmeras, em tempo real e em três dimensões (Chang et al., 2011). Isso sem contar que a terapia fica mais dinâmica e envolvente.

Estudos relatando o uso destas tecnologias ajudam a aumentar a autoeficácia, a autodeterminação e a confiança das crianças ou adolescentes. Um aspecto de grande relevância na reabilitação promovido pela realidade virtual é a possibilidade de uma resposta imediata do paciente em reabilitação; isto é, enquanto em interação com o mundo virtual, o paciente obtém 
feedbacks imediatos da eficiência de suas ações, o que lhe proporciona exigir o máximo de si, estimulando o cérebro/o cerebelo para que façam as correções necessárias para melhorar o desempenho (MONTERO; ZANCHET, 2003; SVEISTRUP, 2004). Além disso, a função motora, o controle postural, os movimentos de alcance, o equilíbrio e a marcha podem ser significativamente melhorados (Chang et al., 2011).

Tendo em vista os benefícios que esse tipo de terapia pode trazer, supõe-se que a aplicação de sessões de jogos funcionais com o sistema Xbox360 Kinect ${ }^{\circledR}$ em crianças, adolescentes e adultos com outras patologias como PC, obesidade, depressão, dor do membro fantasma, dentre outras pode trazer efeitos positivos na recuperação das suas dificuldades motoras. Outro ponto que conta a favor é o baixo custo dessa modalidade de terapia e a facilidade na administração, acessibilidade e suporte técnico acessível já que são equipamentos comerciais (Chang et al., 2011).

Entretanto, os estudos realizados com amputados com desarticulação de quadril são escassos. Assim, o objetivo do presente trabalho foi avaliar os resultados do uso dos jogos funcionais na pré-protetização de paciente com desarticulação de quadril pós osteossarcoma.

\section{Metodologia}

Estudo de natureza qualitativa com abordagem exploratória, que utilizou como procedimento de coleta de dados um estudo de caso, com objetivo de compreender o significado que a fisioterapia lúdica traz para o tratamento fisioterapêutico do indivíduo.

A coleta de dados foi realizada no Núcleo de Atendimento Integrado a Saúde-NAIS, local onde se situa a Clínica Escola de Fisioterapia da Faculdade de Tecnologia e Ciências, em um ambiente tranquilo, com controle da temperatura $\left(24^{\circ} \mathrm{C}\right)$ e propício para a coleta de dados.

Participou deste estudo um voluntário do gênero masculino, 15 anos, $45 \mathrm{Kg}$ de massa corporal e 1,60 metro de estatura corporal, com desarticulação de quadril no membro inferior direito decorrente de Osteossarcoma, há 3 anos e sete meses.

Inicialmente foi realizada a anamnese, na qual foram colhidos dados pessoais do voluntário, características antropométricas, funcionais. Em seguida, para avaliação do desempenho força muscular, equilíbrio e coordenação motora, realizada através de dois instrumentos: os jogos do sistema Xbox360 Kinect, o videogame proporciona uma interface com o jogador que não depende de controles remotos e utiliza câmeras de vídeo, por meio de um sistema de reconhecimento de gestos e sensores de profundidade. A combinação dos sensores possibilita a captura da movimentação do corpo todo, em tempo real e em três dimensões (Chang et al., 2011), mas a Câmera Sony Cyber-Shot Dsc-W830 Preto, para a pontuação ser registrada para posterior análise da curva de evolução. Esses jogos selecionados, de acordo com estudo de Bompa (2002), são a associação entre força, resistência, flexibilidade, coordenação, equilíbrio e velocidade, porque envolvem ajustes posturais necessários. A seleção dos jogos foi direcionada pelas análises das demandas motoras e cognitivas oferecidas por cada um deles e pela presença de fatores potencialmente facilitadores no processo de pré-protetização.

O participante realizou três tentativas por jogo em cada sessão sendo que nas duas primeiras ele foi auxiliado para se movimentar e atingir os objetivos do jogo. Na terceira tentativa jogou sem auxílio e a pontuação foi registrada para posterior análise de dados. A intervenção ocorreu duas vezes por semana, por um período de dois meses, com um total de 11(onze) sessões, de 40 (quarenta) minutos de duração cada, nesse sentido, o adolescente passou por um período de quatro minutos para o reconhecimento de cada jogo, dois minutos para descanso entre um jogo e outro e para a execução de cada jogo proposto o tempo limite era proposto pelo jogo.

As análises dos dados foram processadas e analisadas utilizando-se as informações coletadas do Xbox360 Kinect®, que ao mesmo tempo armazena as filmagens das partidas de cada jogo, no USB 2.0. Posteriormente através da leitura dessas 
filmagens e pontuações dos jogos, foi aplicada em tabela de planejamento terapêutico pré e pós-intervenção. No qual na mesma está contida o pré-teste (como adolescente está realizando os movimentos no jogo), Dificuldade Primárias (por quais motivos está levando-o jogar daquele jeito), Estratégias (quais métodos irá usar para melhorar sua dificuldade), Objetivo Imediato (o que está buscando com esse jogo) e o pós-intervenção (depois de 10 sessões, fazer a análise desses movimentos e seus ganhos). Para estimação dos dados, eles foram tratados no programa Microsoft Office Excel 2010 para serem apresentadas as suas variáveis categóricas de forma que se obtivesse média e desvio das pontuações dos jogos e duração.

Este estudo de caso foi aprovado pelo Comitê de Ética e Pesquisa da Faculdade de Tecnologia e Ciências, sob o número de parecer 2.233.504, atendendo ao que determina a resolução 466/12 (BRASIL, 2012).

\section{Resultado e Discussão}

O presente estudo teve como foco demonstrar os benefícios da aplicação de jogos funcionais como recurso lúdico no tratamento fisioterapêutico oncopediátrico. Utilizando como método avaliativo a Tabela de Planejamento e Tratamento Fisioterapêutico e o Xbox360 Kinect ${ }^{\circledR}$, a partir da análise dos dados referentes ao desempenho dos participantes durante o treino, puderam-se observar aumento estatisticamente significativo nas pontuações em todos os jogos, quando estas foram comparadas às das primeiras sessões de cada jogo, os mesmos forneceram os resultados para o equilíbrio estático e dinâmico, força muscular e coordenação motora, assim melhorando na macha.

\subsection{Hang Gliding (jogo asa delta)}

Neste jogo, o jogador deve movimentar os braços, mantendo os abertos, e ao mesmo tempo, manter o deslocamento do centro de gravidade, ou seja, manter o avatar equilibrado, suportando as forças externas virtuais (ventos, chuvas, declives, montanhas) do jogo, para manter o avatar guiando a asa delta, até chegar ao local de pouso do avatar.

Figura 1 - Aplicação da atividade de equilíbrio, Hang Gliding (Asa delta) na fase de pré-protetização de paciente com desarticulação de quadril pós-osteossarcoma, Feira de Santana-BA, 2018.

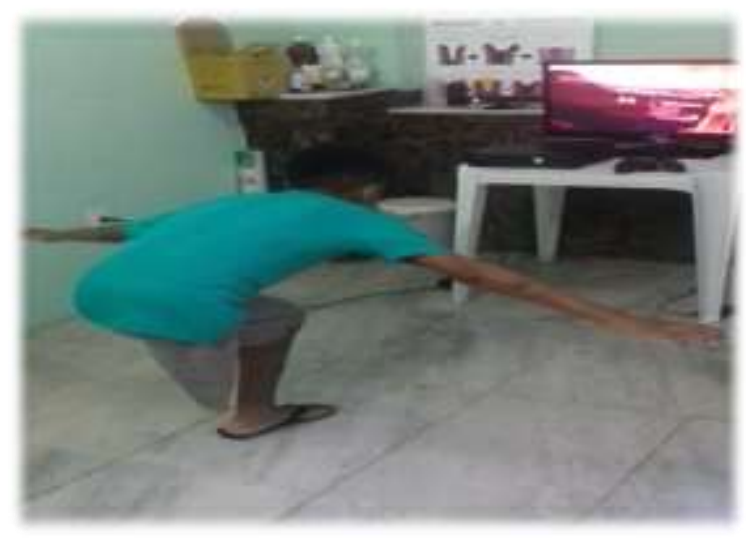

Fonte: Autores (2018).

O objetivo terapêutico deste em foco principal é o equilíbrio, com intuito de melhora na macha. O Quadro 1 abaixo resume as principais demandas motoras e cognitivas do jogo. 
Quadro 1 - Demandas motoras e cognitivas do jogo Hang Gliding (Asa delta).

\begin{tabular}{|l|l|l|}
\hline JOGO & DEMANDA MOTORA & DEMANDA COGNITIVA \\
\hline HANG GLIDING & $\begin{array}{l}\text { Controle antecipatório do equilíbrio; flexão da coluna, coluna } \\
\text { neutra; deslocar ântero-posterior e látero-lateral; } \\
\text { Movimentos dos MMSS flexão e adução de ombro + extensão } \\
\text { de cotovelo. }\end{array}$ & $\begin{array}{l}\text { Atenção aos obstáculos; } \\
\text { Atenção seletiva }\end{array}$ \\
\hline
\end{tabular}

Nota: $\mathrm{CG}=$ centro de gravidade; $\mathrm{MMSS}=$ membros superiores e MMSS =membros inferiores. Fonte: Autores (2018).

O paciente no primeiro dia de atendimento foi submetido a três jogos, começando pelo jogo Asa Delta. Neste jogo o sujeito do estudo apresentou-se conforme o Quadro 2 abaixo.

Quadro 2 - Quadro de Planejamento Tratamento Fisioterapêutico do jogo Hang Gliding (Asa delta).

\begin{tabular}{|c|c|}
\hline Objetivos funcionais & Deficiências secundárias \\
\hline $\begin{array}{l}\text { Longo: controle do centro de gravidade, para manusear a prótese com } \\
\text { facilidade. } \\
\text { Médio: fortalecimento muscular de MIE/abdômen } \\
\text { Curto: descarga de peso } \\
\text { Objetivo imediato }\end{array}$ & \multirow[t]{2}{*}{$\begin{array}{l}\text { Pré Teste: Paciente realizou em ortortase, com flexão de } \\
\text { tronco, com abdução de ombro, com compensações nos } \\
\text { momentos de realizar rotação e flexão de tronco, o mesmo } \\
\text { realizava inclinação lateral, o mesmo chegou ao final do } \\
\text { jogo com bastante dificuldade. }\end{array}$} \\
\hline Descarga de peso & \\
\hline Deficiência Primária & Estratégia: \\
\hline $\begin{array}{l}\text {-Fraqueza muscular de quadríceps, reto abdominal, transverso } \\
\text { abdominal, paravertebrais, tríceps braquial, grande dorsal, isquiotibiais, } \\
\text { tríceps sural, glúteo médio, glúteo mínimo, o tensor da fáscia lata e as } \\
\text { fibras superiores do glúteo máximo, do membro inferior esquerdo } \\
\text { (MIE). } \\
\text {-Descarga de peso, direcionado para o lado acometido o MID. } \\
\text { - Medo de cair }\end{array}$ & $\begin{array}{l}\text {-Fortalecimento de MIE, abdômen. } \\
\text {-Descarga de peso em rampas, cama elástica, prancha } \\
\text { ortostática, balancinho e assim já treinando o equilíbrio. }\end{array}$ \\
\hline Pós Teste: & Observações: \\
\hline $\begin{array}{l}\text { Paciente realizou em ortortase, com flexão de tronco, com abdução de } \\
\text { ombro, mais movimentos combinados de flexão e rotação de tronco para } \\
\text { esquerda e direita, e com total equilíbrio no momento do pouco da asa } \\
\text { delta. }\end{array}$ & $\begin{array}{l}\text { Paciente precisa aprender a descarregar o peso no membro } \\
\text { acometido no MID (membro inferior direito). }\end{array}$ \\
\hline
\end{tabular}

Fonte: Autores (2018).

Foram encontradas dificuldades por parte do paciente, no momento da descarga de peso para manter-se equilibrado, e nos instantes de rotação e flexão de tronco, com abdução do ombro, e no momento do pouso do avatar, controle da descida, devido deficiência secundária, que eram provenientes da deficiência primária, como a fraqueza muscular de quadríceps, reto abdominal, transverso abdominal, paravertebrais, tríceps braquial, grande dorsal, isquiotibiais, tríceps sural, glúteo médio, glúteo mínimo, o tensor da fáscia lata e as fibras superiores do glúteo máximo, do membro inferior esquerdo e o medo de cair. De acordo com Gasparotto, Santos e Fernandes (2012), o fortalecimento de membros inferiores (MMII) influencia significativamente na melhora do equilíbrio. 
Debastiani (2015) observou em seu estudo, que é possível detectar algumas alterações nesses pacientes, sendo que uma dessas alterações é a alteração do equilíbrio corporal, pois a ausência de um dos membros inferiores ocasiona a estes indivíduos, um aumento considerável no risco de quedas.

O equilíbrio é a capacidade que o ser humano tem de se manter ereto ou executar movimentos de aceleração e rotação do corpo sem oscilações ou queda. O equilíbrio corporal é necessário para que o homem exerça suas atividades de vida diárias (AVD’s). O Sistema Nervoso Central (SNC) recebe informações e controla o equilíbrio através do sistema visual, do sistema vestibular, e do sistema somatosensorial ou propriocepção. Qualquer falha ou alteração de uma destas vias de informação pode prejudicar o recebimento da mensagem, alterando a resposta do SNC e causando desconforto ao indivíduo.

Portanto, segundo estudo de Cohen (2001), no caso do indivíduo amputado, irão apresentar bastante dificuldade na reconquista do seu equilíbrio, devido que ele irá perder a propriocepção, ou seja, a aferência dada ao SNC pelos diversos tipos de receptores sensoriais presentes em diferentes estruturas que auxiliam a descrever a consciência da postura, de movimento, e das mudanças no equilíbrio, assim como o conhecimento da posição, do peso e da resistência dos objetos em relação ao corpo, sendo assim o amputado terá somente as informações proprioceptivas ao nível da região do coto, que serão enviadas ao SNC.

Após a decima primeira sessão do mesmo jogo, foi encontrada uma melhora do equilíbrio, com total controle de tronco e do centro de gravidade, com as descargas de peso corporal, sem medo de cair, que também pode ser visto no Gráfico1, abaixo:

Gráfico 1 - Médias e erros padrão das pontuações do participante no jogo Hang Gliding (Asa delta), em todas as sessões de treino na fase de pré-protetização de paciente com desarticulação de quadril pós-osteossarcoma, Feira de Santana-BA, 2018.

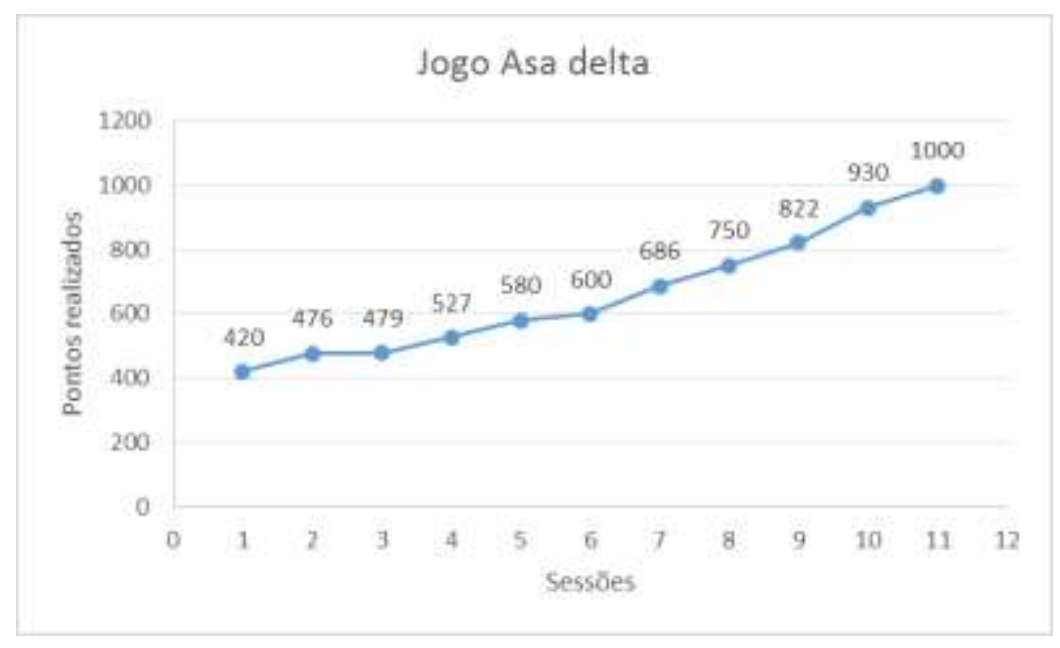

Fonte: Autores (2018).

A Gráfico 1 mostra que, em relação ao jogo Asa delta, houve aumento da pontuação ao longo das sessões, com modificação a partir da $2^{\mathrm{a}}$ sessão, que se manteve até a $11^{\mathrm{a}}$ sessão.

Esses achados se a assemelham aos encontrados por Jaime et al., (2016), em seu estudo sobre: A influência do Kinect na melhora do equilíbrio, força e agilidade em idosos institucionalizados na cidade de São Luís de Montes Belos-GO. Os autores selecionaram uma amostra composta por 6 indivíduos do sexo masculino, entre 70 a 85 anos. Foi aplicado o teste de Apoio Uni Podálico, teste de levantar e caminhar por 2,5 metros, e o teste de Levantar da cadeira em 30 segundos. Realizadas 10 sessões com o Videogame Xbox 360 acompanhado do sensor Kinect, com jogo Adventure da marca Microsoft. Os resultados apontam para melhora do equilíbrio em relação ao apoio unipodal, onde no início da sessão o paciente não 
demostrava capacidade de manter por 5 segundos, e no último atendimento já conseguia média de 26 a 43 segundos. Contudo o grupo de intervenção apresentou melhora em relação perante a força, agilidade e equilíbrio em idosos.

Assim como Kayama et al., (2014), em seu estudo sobre Efeito de um jogo Kinect baseado em exercício em melhorar o desempenho cognitivo Executivo em residentes na comunidade Idosos: Estudo de Caso de controle e Deutsch et al., (2008), o uso do Kinect é uma excelente ferramenta para melhorar a saúde física, no que diz respeito ao condicionamento físico, equilíbrio e consequentemente melhora na agilidade, por trabalhar em conjunto com concentração agilidade para conseguir realizar os jogos. Um estudo realizado por Junior et al., (2014), apresentou resultados positivos de treino de equilíbrio postural para melhorar a performance de jogadores de futebol com histórico de lesão em membro inferior, sendo assim os resultados demonstrando pontos positivos para a terapia com os jogos do Xbox 360 Kinect@ foi tão eficaz no treino de equilíbrio corporal e postural.

\section{2: Horseback Riding (cavalgando)}

Neste jogo, o avatar do jogador se mantém montado em um cavalo, dentro de uma arena de hipismo, o jogador tem que movimentar rapidamente partes do corpo, para guiá-lo, e deve desviar dos obstáculos.

Figura 2 - Aplicação da atividade de coordenação motora Horseback Riding (cavalgando) na fase de pré-protetização de paciente com desarticulação de quadril pós-osteossarcoma, Feira de Santana-BA, 2018.

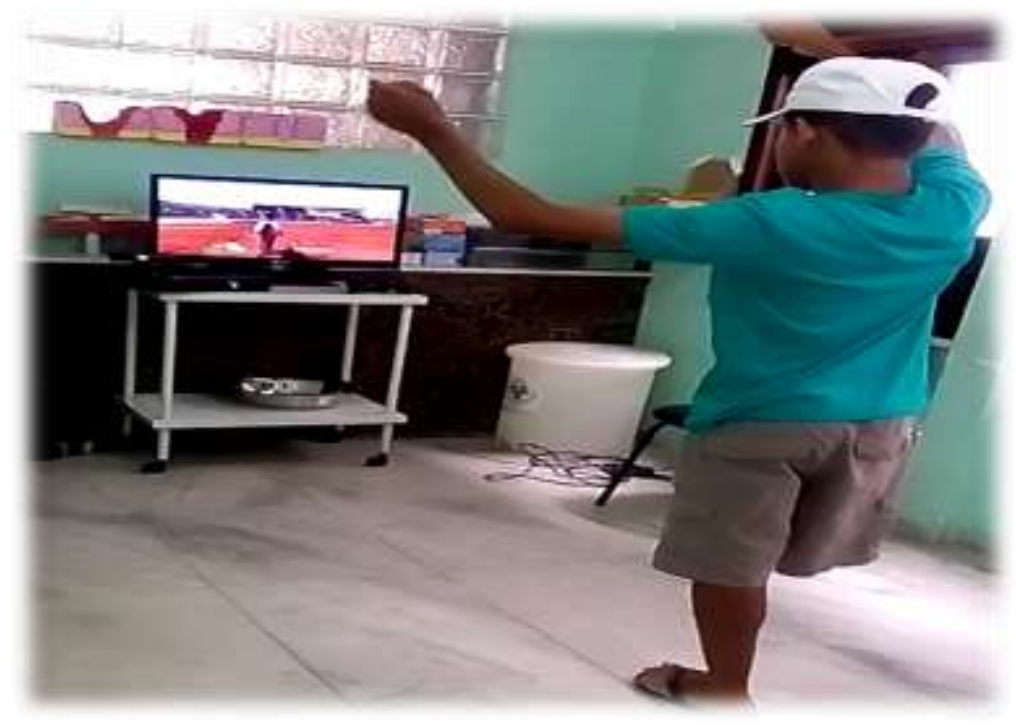

Fonte: Autores (2018).

O intuito deste jogo tem como objetivo principal trabalhar a coordenação motora, mas o equilíbrio e a cardiorrespiratória também são itens presentes neste jogo, e assim melhorando nas suas atividades diárias e marcha. O Quadro 3 abaixo resume as principais demandas motoras e cognitivas do jogo. 
Quadro 3 - Demandas motoras e cognitivas do jogo Horseback Riding

\begin{tabular}{|l|l|l|}
\hline JOGO & DEMANDA MOTORA & DEMANDA COGNITIVA \\
\hline & $\begin{array}{l}\text { Movimentos de MMSS extensão e flexão de cotovelo + } \\
\text { HORSEBACK }\end{array}$ & \\
RIDING & $\begin{array}{l}\text { - Deslocano, flexão+abdução e rotação interna de ombro; } \\
\text { - Flexão de coluna; inclinação latero-lateral de coluna para fazer } \\
\text { o percurso; } \\
\text { - Flexão de quadril e joelho para saltar os obstáculos. }\end{array}$ & $\begin{array}{l}\text { - Planejar movimentos de MMSS; } \\
\text { - Atenaos obstáculos. }\end{array}$ \\
\hline
\end{tabular}

Nota: $\mathrm{CG}=$ centro de gravidade; $\mathrm{MMSS}=$ membros superiores e MMSS =membros inferiores. Fonte: Autores (2018).

No segundo jogo, sujeito do estudo foi submetido ao jogo Cavalgando, como pode ser visto na Tabela 4 abaixo.

Quadro 4 - Tabela de Planejamento Tratamento Fisioterapêutico.

\begin{tabular}{|l|l|}
\hline Objetivos funcionais & Deficiências secundárias (como?) \\
\hline Longo: imagem corporal, para receber a prótese. & $\begin{array}{l}\text { Pré-teste: Paciente iniciou jogo em ortortase com movimentos } \\
\text { combinados MMSS extensão e flexão de cotovelo + extensão, } \\
\text { flexão+abdução e rotação interna de ombro para movimentar } \\
\text { a corda do cavalo virtual e guia-lo. Mas nos movimentos de } \\
\text { saltar os obstáculos e ao mesmo tempo agachar o paciente } \\
\text { realizou com dificuldades, pois o mesmo não coordenava o } \\
\text { movimento de guia o cavalo e pular ao mesmo tempo. }\end{array}$ \\
\hline Objetivo imediato & Estratégias \\
\hline Consciência corporal & $\begin{array}{l}\text { Exercícios usando vários movimentos ao mesmo tempo como, } \\
\text { agregar a bola, halteres, faixa elástica, para o paciente utilizar } \\
\text { ao mesmo tempo em que tiver fazendo o exercício. }\end{array}$ \\
\hline Def. primárias & $\begin{array}{l}\text { Observações: } \\
\text { - Consciência corporal }\end{array}$ \\
\hline $\begin{array}{l}\text { - Medós-teste: } \\
\text { Paciente iniciou jogo em ortortase com os movimentos de MMSS } \\
\text { extensão e flexão de cotovelo + extensão, flexão+abdução e rotação } \\
\text { interna de ombro, com controle do deslocamento ântero-posterior e } \\
\text { látero-lateral do CG; com flexão de coluna; inclinação latero-lateral de } \\
\text { coluna para fazer o percurso, e sem dificuldades para flexão de quadril } \\
\text { e joelho para saltar os obstáculos. }\end{array}$ & $\begin{array}{l}\text { Paciente requer mais consciência corporal, e perder o medo de } \\
\text { cair, descarga de peso. }\end{array}$ \\
\hline
\end{tabular}

Fonte: Autores (2018).

Como pode ser visualizado na tabela acima no momento da descarga de peso, e coordenar os movimentos de MMSS e MIE foram suas maiores dificuldades encontradas, ou seja, suas deficiências secundárias, provenientes de suas deficiências primárias, como consciência corporal, descarga de peso direcionado para o lado acometido o MID, medo de cair. Segundo estudo de Monteiro (2012), essas alterações acontecem devido à perda de parte do corpo, o sujeito pode sofrer uma alteração brusca da imagem corporal, assim causando uma percepção negativa da própria imagem corporal, cria dificuldades para conscientização das atividades musculares e para aquisição de posturas corretas no processo de reabilitação. Segundo Enoka (2000), em vários estudos realizados pôde observar que a coordenação motora é um aspecto do desenvolvimento humano que está em constante desenvolvimento, podendo passar por transformações a depender da condição devida e das situações, e no caso do amputador a sua coordenação motora é afetada devido à perda de um membro, onde o mesmo tem que aprender a se reorganizar como um todo.

Após a decima primeira sessão do mesmo jogo, foi notada grande evolução do paciente como pode ser visto na Tabela 3 acima, e no Gráfico 2 abaixo. 
Gráfico 2 - Médias e erros padrão das pontuações dos participantes no jogo Horseback riding (cavalgando), em todas as sessões de treino na fase de pré-protetização de paciente com desarticulação de quadril pós-osteossarcoma, Feira de SantanaBA, 2018.

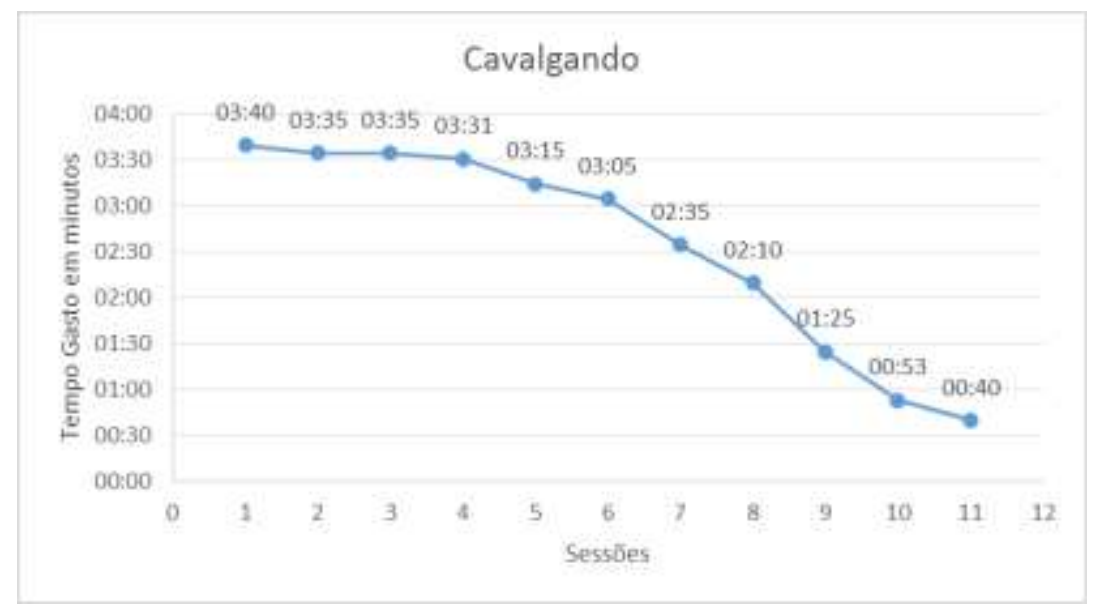

Fonte: Autores (2018).

Melhor desempenho ao longo das sessões pôde também ser observado no jogo Cavalgando, conforme mostra o gráfico 2. Entretanto, o melhor desempenho em relação à primeira sessão foi observado a partir da $4^{a}$ sessão, mantendo-se até a $11^{\mathrm{a}}$ sessão.

Paciente se mostrou com total consciência corporal, e descarga de peso, estes achados assemelham-se aos encontrados por Bocolini (2000), em seu estudo sobre Efeito da participação em física atividade na imagem corporal de amputados, afirma que devido ao uso do vídeo game com Kinect melhorou a agilidade e coordenação dessas pessoas, aumentam a confiança e melhoram a sensação de controle do próprio físico. Já ChuanJun (2013), em seu estudo relata que o uso do Kinect na área da fisioterapia atua de forma significante, na melhora das agilidades, marcha e coordenação motora. Por explorar as habilidades usadas no cotidiano (caminhar, saltar, agachar), o que permite ao usuário utilizar seu próprio condicionamento para interagir com os jogos, e ainda se adaptar aos jogos, podendo treinar e ampliar suas capacidades para realização dos mesmos. Isso tudo significa mais um ponto positivo para o uso dos jogos funcionais na fisioterapia.

\subsection{Boxing (boxe)}

Neste jogo, o avatar do jogador está dentro de plataforma chamada ringue formado por 4 lados. Os jogadores têm que movimentar partes do corpo para nocautear o avatar adversário. 
Figura 3: Aplicação da atividade de ganho de força muscular e resistência cardiorrespiratória, Boxing (Boxe) na fase de préprotetização de paciente com desarticulação de quadril pós-osteossarcoma, Feira de Santana-BA, 2018.

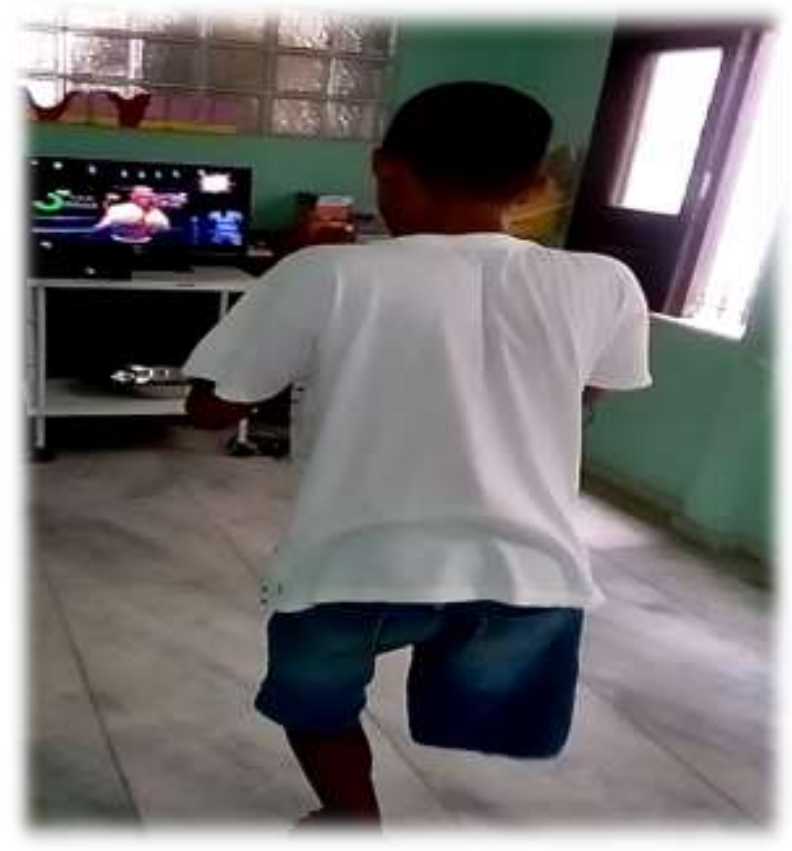

Fonte: Autores (2018).

O foco maior deste jogo é a força muscular e resistência cardiorrespiratória, assim melhorando sua resistência e força para receber a prótese. O Quadro 5 abaixo resume as principais demandas motoras e cognitivas do jogo.

Quadro 5 - Demandas motoras e cognitivas do jogo Boxing (Boxe)

\begin{tabular}{|l|l|l|}
\hline JOGO & DEMANDA MOTORA & DEMANDA CONGNITIVA \\
\hline \multirow{3}{*}{ BOXING (BOXE) } & $\begin{array}{l}\text { Movimentos dos MMSS e cabeça, extensão e flexão de cotovelo } \\
\text { + extensão, flexão e rotação interna de ombro; } \\
\text { Movimento de MMII: flexão e extensão de quadril e joelho; } \\
\text { ântero-posterior e látero-lateral; } \\
\text { Passos multidirecionais; controle do equilíbrio. }\end{array}$ & $\begin{array}{l}\text { Planejamento de movimentos; } \\
\text { Tempo de reação; } \\
\text { tenção a vários alvos (golpes) e dupla } \\
\text { tarefa. }\end{array}$ \\
\hline
\end{tabular}

Nota: $\mathrm{CG}=$ centro de gravidade; $\mathrm{MMSS}=$ membros superiores e MMSS =membros inferiores. Fonte: Autores (2018).

O jogo de boxe foi o terceiro jogo a ser aplicado para o sujeito do estudo conforme Quadro 6 abaixo: 
Quadro 6 - Tabela de Planejamento Tratamento Fisioterapêutico.

\begin{tabular}{|c|c|}
\hline Objetivos funcionais & Deficiências secundárias (como?) \\
\hline $\begin{array}{l}\text { Longo: independência da macha para receber a prótese. } \\
\text { Médio: melhora cardiorrespiratória } \\
\text { Curto: fortalecimento muscular de MIE/abdômen } \\
\text { Objetivo imediato } \\
\text { Descarga de peso }\end{array}$ & $\begin{array}{l}\text { Pré-teste: paciente inicia jogo em ortortase, com movimentos } \\
\text { combinados de MMSS e MIE, de flexão de ombro, flexão e } \\
\text { extensão de cotovelo. Mas sua maior dificuldade é nos movimentos } \\
\text { agachar e nocautear o adversário, com movimentos rápidos. }\end{array}$ \\
\hline Def. primarias & Estratégias \\
\hline $\begin{array}{l}\text {-Fraqueza muscular, reto abdominal, transverso abdominal, } \\
\text { paravertebrais, tríceps braquial, bíceps braquial, grande dorsal, } \\
\text { isquiotibiais, tríceps sural, glúteo médio, glúteo mínimo, o tensor } \\
\text { da fáscia lata e as fibras superiores do glúteo máximo, do membro } \\
\text { inferior esquerdo (MIE). } \\
\text { - Fraqueza muscular do músculo estriado esquelético }\end{array}$ & $\begin{array}{l}\text { Fortalecimento muscular global } \\
\text { Treinos aeróbicos } \\
\text { Alongamentos globais }\end{array}$ \\
\hline Pós-teste: & Observações: \\
\hline $\begin{array}{l}\text { Paciente realizou jogo com todos os movimentos combinados dos } \\
\text { MMSS e cabeça, extensão e flexão de cotovelo + extensão, flexão } \\
\text { e rotação interna de ombro; } \\
\text { Movimento de MMII: flexão e extensão de quadril e joelho; } \\
\text { ântero-posterior e látero-lateral; } \\
4 \\
\text { Passos multidirecionais; controle do equilíbrio. }\end{array}$ & $\begin{array}{l}\text { A mesma fadiga com facilidade, e assim diminuindo a intensidade } \\
\text { no jogo. }\end{array}$ \\
\hline
\end{tabular}

Fonte: Autores (2018).

Paciente apresentou deficiências secundárias, como agachar e realizar movimentos rápidos com intensidade, isso tudo decorrente da deficiência primária como, fraqueza muscular de reto abdominal, transverso abdominal, paravertebrais, tríceps braquial, bíceps braquial, grande dorsal, musculatura de cadeia anterior de coxa, que incluem os flexores de quadril e extensores do joelho, quadríceps femural. Em cadeia posterior da coxa, podemos destacar a atuação dos ísquiotibiais, responsáveis pela extensão de quadril e pela flexão do joelho. Além disso, podemos também salientar a importância dos plantiflexores do tornozelo (tríceps surral), dorsiflexores do tornozelo (tibial anterior), adutores e abdutores do quadril e ressaltando fraqueza muscular do músculo estriado esquelético.

Almeida et al., (2009) afirmam em estudo, que essas alterações geralmente envolvem um maior deslocamento do centro de massa muscular e um aumento no gasto energético como mecanismo de compensação da perda do membro. Consideravelmente outros autores afirmam em estudo, Malta Jabo et al., (2009), que quanto mais proximal o nível de amputação, maiores são essas alterações, maior será o gasto energético do paciente ao efetuar manobras para se adaptam com mais facilidade e os custos financeiros poderão ser maiores, o retorno mais demorado do amputado ao convívio social e profissional, assim, exigindo mais da sua capacidade respiratória e sua força muscular.

No último atendimento, especificado na décima primeira sessão, paciente já realizava agachamento com descarga de peso, e utilizava MMSS coordenados com MIE com facilidades. Também como pode ser visto no Gráfico 3 abaixo. 
Gráfico 3 - Médias e erros padrão das pontuações dos participantes no jogo Boxing (Boxe), em todas as sessões de treino, na fase de pré-protetização de paciente com desarticulação de quadril pós-osteossarcoma, Feira de Santana-BA, 2018.

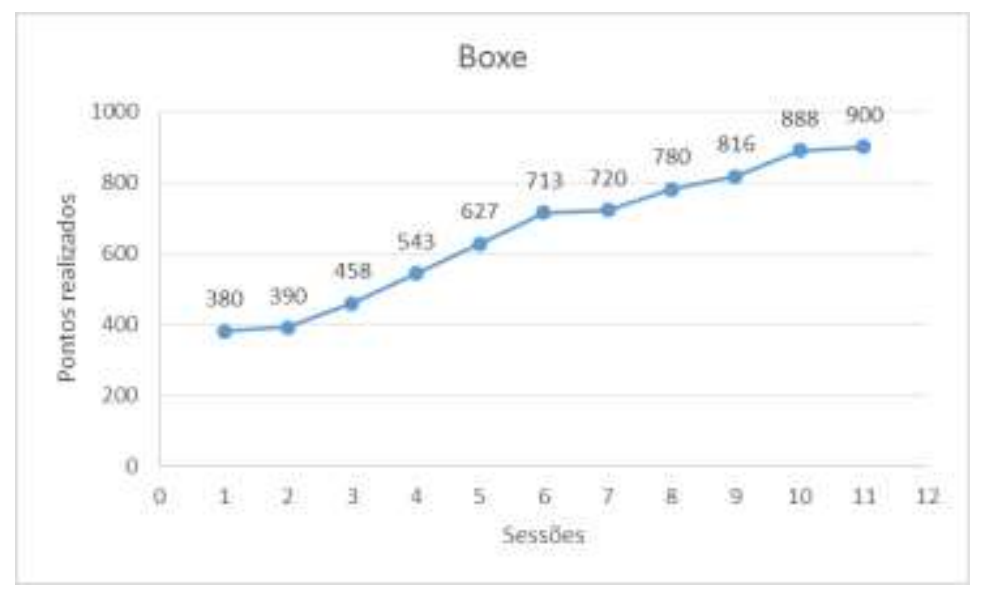

Fonte: Autores (2018).

Esses achados assemelham-se aos encontrados por Pompeu (2012), em seu estudo sobre Melhora funcional de pacientes com Doença de Parkinson que após treinamento em ambiente real e virtual, relata que devido à praticidade e ao uso do próprio peso do indivíduo, os exercícios executados ao realizar os jogos com kinect possibilita que o indivíduo tenha melhoras significativas no quesito força por exigir movimentos variados. Na mesma direção, Freitas (2012), em seu estudo sobre Desenvolvimento e Avaliação de um Jogo de Reabilitação Motora baseado em Kinect, destacam que o uso de jogos com o acessório Kinect, interfere positivamente no ganho de força, por exigir de seus jogadores a realização de exercícios com movimentos sincronizados como salto, desvios laterais, agachamento, chutes, abdução, adução para realizar os jogos, que proporcionam o reforço muscular de MMII.

\section{Considerações Finais}

O presente estudo evidenciou que o uso do vídeo game Xbox360 Kinect $®$ foi capaz de influenciar de forma positiva em todas as variáveis analisadas, como força, coordenação motora e equilíbrio. A coordenação motora, que houve maior dificuldade, mas na quarta avaliação foi significativamente maior do que a avaliação inicial. Da mesma forma, o equilíbrio e a forca muscular também melhoraram consideravelmente após as dez sessões com auxílio do Kinect.

Portanto o presente trabalho deixa claro que a terapia com o Kinect mostrou-se eficiente na melhora da força, agilidade e coordenação motora em amputado unilateral de desarticulação de quadril pós-osteossarcoma.

É válido ressaltar que o lúdico tem se mostrado como catalisador no processo de recuperar a capacidade de adaptação, tão necessária nesse momento de mudanças bruscas. O lúdico ao proporcionar a oportunidade de escolhas e linguagem de seu domínio favorece que o sujeito se coloque como agente ativo, também podendo desempenhá-lo em seu próprio tratamento (LOPES et al., 2000). Ou seja, propicia uma postura pró-ativa implicando em maior autonomia, o que pode repercutir de forma positiva em sua autoestima e na capacidade de resolução de problemas, bem como possibilitar maior adesão ao tratamento.

Por fim, nesse intuito, a terapia com Kinect desenvolvida com essa pesquisa mostra que o mesmo pode e deve ser um recurso de ludicidade aplicável para melhorar diversos parâmetros funcional e emocional do adolescente.

\section{Referências}

Almeida, L F, Camargos, G V, \& Corrêa, L C. (2009). Mudanças reorganizacionais nos córtices somatossensorial e motor em amputados: Revista Neurociência. São Paulo, v 30, n 5, p. 146-155, 2009. 
Alves, C. L (2016). Efeito do exergame zumba fitness sobre o estado de ansiedade em mulheres jovens. Revista Brasileira de Educação Física e Esporte. São Paulo, 65(5), 30-35, Mar 2016.

Amadio S. (2000). A. Metodologia biomecânica para estudo das forças internas ao aparelho locomotor: importância e aplicações no movimento humano. São Paulo: Estação Liberdade.

Bocolini, F. (2000). Reabilitação - Amputados, Amputações e Próteses. (2.ed.), São Paulo: Robe.

Bompa, O. P. (2002). Gameterapia para crianças com Paralisia Cerebral. 2002. 68 p. Monografia (Trabalho de Conclusão do Curso de Bacharel em Fisioterapia) - Centro Universitário USP, São Paulo.

Camargo, A. (2013). O resgate do prazer de brincar da criança com câncer no espaço hospitalar. Rev Assoc Med Bras. 20(5), 29-35.

Chang, R; Chen, C; Hang, F A. (ed.). (2011). Medicina da Reabilitação. São Paulo: FEALQ.

Chuanjun, S. U. (2013). Personal Rehabilitation Exercise Assistant with Kinect and Dynamic Time Warping. International Journal of Information and Education Technology, 3(4).

Debastiani, J. C. (2015). Avaliação do equilíbrio e funcionalidade em indivíduos com amputação de membro inferior protetizados e reabilitados. Revista brasileira de enfermagem, ribeirão preto, 65(5), 32-36.

Deutsch, J. E. et al. (2008). Use Of a Low Cost, commercially Available goming console (WII) for Reabilitation of Adolescent with Cerebral palsy. Revista Physical Therapy, 88(10).

Enoka, R. M. (2000). Bases neuromecânicas da cinesiologia. Manole.

Freitas, D. Q. (2012). Development and Evaluation of a Kinect Based Motor Rehabilitation Game. Revista XI SB Games. 2(4), Brasília-DF.

Gasparotto, P. R.; Santos, J. F.; Fernandes Q. (2012).A importância da análise dos gêneros para fisioterapeutas: enfoque nas quedas entre idosos. Rev. Fisioterapia Movimento. Curitiba, 25(4), 701-707.

INCA - Instituto Nacional de Câncer José Alencar Gomes da Silva. (2016). Coordenação de Prevenção e Vigilância. Estimativa 2016: incidência de câncer no Brasil. Rio de Janeiro: INCA. 2015 [citado em 2017 ago. 17].

Jaime, E. (2016).. Jogos materno-infantis: estimulação essencial para a criança com paralisia cerebral. Revista Estudos de Psicologia, Campinas, 65(5), .65-73, Mar..

Junior, V. D. S., et al., (2014). Mover Serious Game aplicado à reabilitação motora usando sensor de movimento Kinect Escola de Artes. Revista de Ciências e Humanidades Universidade de São Paulo (USP), São Paulo, 29(5), 30-33.

Kayama, H. K. et al. (2014). Efeito de um jogo Kinect baseado em exercício em melhorar o desempenho cognitivo Executivo em residentes na comunidade Idosos, Estudo de Caso de controle. Fardoun $\mathrm{H}$, ed Journal of Medical Internet.

Lopes, L. F. et al. (2000). Os efeitos tardios do tratamento do câncer infantil. Revista da Associação Médica do Brasil. São Paulo, 35(5), 277-280.

Malta J. D. S. et al. (2009). O momento do diagnóstico e as dificuldades encontradas pelos oncologistas pediátricos no tratamento do câncer em Belo Horizonte. Revista brasileira cancerol. Belo Horizonte, 30(6), 33-39.

Monteiro, K. (2012). Gasto energético em paciente amputado transtibial com prótese e muletas. Acta fisiátrica. São Paulo, 35(10), 32-34.

Perraro, L. F. (2012). Aplicação dos jogos funcionais para idosos utilizado o Kinect. Revista de Fisioterapia Movimento. Curitiba, $25(4), 62-68$.

Pompeu, J. E. (2012). Melhora funcional de pacientes com Doença de Parkinson após treinamento em ambiente real e virtual. Universidade de São Paulo, Instituto de Psicologia, Departamento de neurociência e comportamento, São Paulo.

Resende, M. C. et al. (2004). Rede de relações e satisfação com a vida em pessoas com amputação de membros. Revista Ciências e Cognição. Rio de Janeiro, 20(5), 164-177. 